\title{
Vicarious Grief in Supervision: Considerations for Doctoral Students Supervising Counselors-in-Training
}

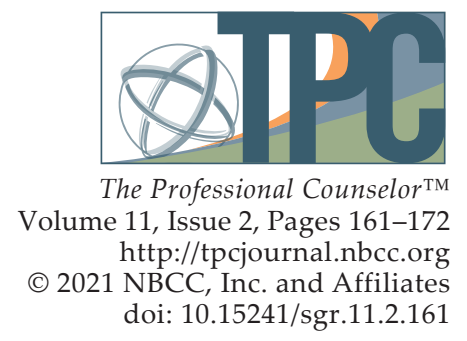

Samara G. Richmond, Amber M. Samuels, A. Elizabeth Crunk

The COVID-19 pandemic has brought about collective experiences of grief; thus, counselors-in-training (CITs) and their doctoral student supervisors may encounter increases in grief-oriented clinical work. In considering how to support CITs' work with grieving clients, doctoral supervisors should be prepared to help CITs manage experiences of vicarious grief (VG). Given the ubiquity of loss and the limited amount of grief-specific coursework in counselor training, CITs could benefit from exploring their experiences of VG with their doctoral supervisors in clinical supervision - a core area of training for doctoral students enrolled in counselor education programs accredited by the Council for Accreditation of Counseling and Related Educational Programs. In this manuscript, we (a) provide an overview of the literature on VG, (b) discuss the potential impact of VG on CITs, (c) present a case study illustrating attention to VG in supervision, and (d) provide practical strategies doctoral supervisors can employ when addressing VG in supervision, drawing on Bernard and Goodyear's discrimination model.

Keywords: vicarious grief, counselors-in-training, doctoral supervisors, clinical supervision, discrimination model

Loss, and the resulting grief response, is a universal human experience that individuals are likely to encounter at multiple points across the life span (Chan \& Tin, 2012). As such, grief presents in counseling as a common client concern (Hill et al., 2018) and can stem from the loss of a loved one through death, non-death loss (e.g., relationship loss, loss of lifestyle), or normal life transitions (e.g., retirement, relocating; Sullender, 2010). Given the ubiquity of these experiences, counselors should anticipate working with clients who are facing loss and grief throughout their years of practice (Doughty Horn et al., 2013).

Current events may also elicit collective and global grief responses as we have seen with the COVID-19 pandemic and the unexpected death of professional basketball player Kobe Bryant early in 2020 (Milstein, 2017; Weir, 2020). These bring the pervasiveness of grief to the forefront of our awareness. Counselors, not immune to these events at the macro or micro level, must cope with their own grief responses and be prepared to experience grief through exposure to their clients' presenting concerns, recognized as a vicarious grief(VG) response (Chan \& Tin, 2012; Kirchberg et al., 1998; Rando, 1997). This reality, highlighted by the growing awareness and impact of collective grief in 2020, supports the need for increased loss and grief competencies within the profession of counseling.

Although calls have been made to more purposefully integrate loss and grief competencies into counselor education (Doughty Horn et al., 2013), we aim to highlight the importance of supporting doctoral students in growing loss and grief competencies related to their roles as future counselor educators and supervisors. As the most recent Council for Accreditation of Counseling and Related

Samara G. Richmond, MA, MS, NCC, LGPC, is a doctoral candidate at The George Washington University. Amber M. Samuels, MS, NCC, LGPC, is a doctoral candidate at The George Washington University. A. Elizabeth Crunk, PhD, NCC, LGPC, is an assistant professor at The George Washington University. Correspondence may be addressed to Samara G. Richmond, 2136 G St NW, Washington, D.C. 20052, sgelb@gwmail.gwu.edu. 
Educational Programs (CACREP) standards identify supervision as one of the five core areas of doctorallevel student training (CACREP, 2015), we propose that doctoral students should be trained to identify VG observed within counselors-in-training (CITs) and themselves. Further, they should be prepared to facilitate supervisory discussion to explore VG and help CITs learn strategies for effectively managing VG they might experience in response to their clinical work. Drawing on the existing literature on vicarious trauma, loss, and grief in counseling and supervision, as well as Bernard and Goodyear's $(1992,2019)$ discrimination model, with this article we (a) provide an overview of the literature on VG, (b) discuss the potential impact of VG on CITs, (c) present a case study illustrating VG in supervision, and (d) provide practical strategies doctoral supervisors can employ when addressing VG in supervision.

\section{Grief in Counseling}

In order to more thoroughly understand counselors' and supervisors' experiences of VG, it is necessary to first explore how loss and grief may present within the therapeutic context. Contrary to traditional stage models of bereavement, contemporary research indicates that grief is a more nuanced, nonlinear psychological response to loss that can vary significantly between individuals with respect to duration of grief and the presentation and intensity of symptoms (Crunk et al., 2017; Doughty Horn et al., 2013). For example, although the majority of individuals experience more normative grief responses, about $10 \%$ of bereaved individuals experience a protracted, debilitating, and sometimes life-threatening grief response known as complicated grief (Shear, 2012), also referred to as prolonged grief disorder (Prigerson et al., 1995) or persistent complex bereavement disorder (American Psychiatric Association, 2013). As doctoral student supervisors and CITs inevitably encounter clinical presentations of loss and grief, the ability to identify and discuss both common and complicated grief reactions not only serves to support determination of treatment interventions, but also promotes the introspection necessary to identify, explore, and cope with their own VG responses (Ober et al., 2012), which is the focus of this present article.

\section{Vicarious Grief}

Prior literature within the counseling profession has largely focused on vicarious trauma-the negative emotional or psychological changes and altered view of self, others, or the world experienced by counselors resulting from repeated engagement with clients' trauma-related stories, memories, pain, and fear (American Counseling Association [ACA], n.d.; Trippany et al., 2004). It is widely recognized by practitioners and counselor educators that vicarious trauma can be personally and professionally disruptive, with counselors experiencing behavior changes, interpersonal issues, shifts in personal values and beliefs, and diminished job performance as a result (ACA, n.d.). However, less attention has been directed toward VG (i.e., bereavement), a phenomenon originally documented by Kastenbaum (1987) that describes "the experience of loss and consequent grief and mourning that occurs following the deaths of others not personally known by the mourner" (Rando, 1997, p. 259). The two types of VG include (a) Type 1, exclusively VG (i.e., the griever feels what it is like to be in the initial griever's position) and (b) Type 2, the experience of VG for a griever along with feeling reminded of one's own losses and unfinished grieving (Rando, 1997; Sullender, 2010). Although there is overlap between grief and trauma, there are also important differences for counselors to be aware of and attend to in counselor training, practice, and supervision, particularly given the pervasiveness of loss and grief.

In light of prior literature suggesting that counselors can experience negative outcomes following vicarious traumatization, we propose that issues of loss and grief, too, can elicit unexpected and unwanted grief responses that might impact counselors' well-being or even their ability to provide client care. CITs and doctoral supervisors would benefit from greater awareness of the potential impacts of VG on themselves and their ability to deliver ethical and effective services to clients. Research 
has indicated training and experience in grief counseling are among the strongest predictors of grief counseling competence (Ober et al., 2012); thus, counselors who have little or no training in grief and loss may be at risk for being unable to manage clients' grief presentations. With counselor wellness essential to providing adequate clinical services, and counselors holding an ethical obligation to be prepared to work with a variety of client presentations, including loss and grief, it is suggested that increased attention to VG serves to promote counselor wellness, clinical preparedness, and positive client outcomes (Hill et al., 2018).

Although the long-term effects of our current experiences of collective, widespread grief have yet to be fully identified and understood, the immediate impact brings to the forefront the professional necessity of recognizing reactions to grief within clinical work and supervision. Sufficient evidence exists that counselors who work with clients facing issues of loss and grief are vulnerable to compassion fatigue, burnout, and secondary traumatization. Best practices reflect the necessity for practitioners to attend to their emotional responses to clients presenting with these issues (Chan \& Tin, 2012; Gentry, 2002; Kirchberg et al., 1998), but little empirical evidence has been established surrounding how counselors respond to discussion of loss and grief in supervision. Therefore, to promote recognition and understanding of VG, it is beneficial for counselors and counselor educators to consider the separate and distinct impacts of VG on a counselor's work. This includes how VG can permeate into supervisory relationships - space that has traditionally been used for counselors to process and attend to their emotional reaction to clients' presenting concerns (Bernard \& Goodyear, 2019).

\section{Vicarious Grief in Supervision}

Although supervision is evaluative and hierarchical by nature, it can serve a "simultaneous purpose of enhancing the professional functioning" (Bernard \& Goodyear, 2019, p. 9) of the CIT. When applied to loss- and grief-oriented clinical work, it may be understood to include assisting CITs in exploring how their own reactions contribute to their ability to deliver clinical services. For doctoral students in the role of supervisor, this task requires that they not only support the connection of classroom learning to clinical practice, but also promote personal reflection and growth in the service of clients. As such, in cases of clients presenting with issues of loss and grief, doctoral students can utilize supervision and the supervisory working alliance to facilitate identification and understanding of a VG response, ultimately supporting more effective clinical work.

The supervision literature suggests that VG may affect counselors differently depending on their level of clinical experience. For example, more advanced clinicians have been found to experience less distress when faced with death-related client concerns (Terry et al., 1996), whereas beginning counselors, particularly those in a practicum course, rate death and loss as highly uncomfortable clinical topics to handle (Kirchberg \& Neimeyer, 1991). In addition, the interplay of personal and contextual factors may exacerbate the distress that students experience when faced with these clinical topics, emphasizing the necessity of not only acquiring appropriate knowledge and skills related to grief work, but also personal awareness and competencies to manage their emotional responses (Chan \& Tin, 2012; Kirchberg et al., 1998). Doctoral students must be prepared through their own education and introspective abilities to support this process for their CITs.

As it presents for CITs, sufficient evidence can be derived from the loss and grief and vicarious trauma literature to suggest that client outcomes may be affected when CITs cannot adequately identify or cope with vicarious responses (ACA, n.d.; Hill et al., 2018). When experiencing VG, it may be more difficult for CITs to attend to client presentations during session and engage in pre-session planning or post-session reflection (Lonn \& Haiyasoso, 2016). Without standards for grief training or practice in the 
professional counseling field (Doughty Horn et al., 2013; Ober et al., 2012), much of the responsibility to promote CIT wellness and attention to VG responses falls on doctoral student supervisors engaging with CITs in their practicum experiences. As such, doctoral student supervisors, also ethically charged with promoting client welfare and proficiency of practitioners across presenting concerns, should be prepared to attend to VG and its likelihood to impact CIT ability to lead client sessions effectively.

Given that the vicarious trauma literature suggests that supervisors monitor their own responses to trauma-focused clinical information presented by their CITs, doctoral student supervisors and their supervisors (i.e., counselor educators and supervisors) supporting grief work must also be aware of their own risk for VG (Lonn \& Haiyasoso, 2016). Supervisors may also experience emotional reactions to CITs' disclosures of their own VG reactions in supervision (Bernard \& Goodyear, 2019). Through utilizing introspective practices, doctoral student supervisors and their supervising counselor educators and supervisors can attend to this heightened possibility of VG by examining their physical, emotional, and cognitive reactions to their CITs, their workload, and any personal issues pertaining to unresolved grief that may be shaping how they in turn conduct supervision around topics of loss and grief (Ladany et al., 2000; Walker \& Gray, 2002, as cited in Bernard \& Goodyear, 2019). The following sections outline recommendations for addressing VG in supervision with doctoral-level supervisors and CITs.

\section{Supervision and Vicarious Grief: Leveraging Roles and Relationships}

Clinical supervision is essential to basic counselor training and has become a major emphasis of counseling doctoral training programs (Bernard \& Goodyear, 2019; CACREP, 2015). Supervision as a practice has been found to increase counselor objectivity, empathy, and compassion (Trippany et al., 2004), providing an ideal environment for doctoral student supervisors to intervene and address the ripple effects of client grief presentations. Although grief is a common client concern, literature addressing VG in supervision is scarce. Generally recognized standards for addressing VG in supervision do not yet exist. Thus, in the absence of best practices, in this article, we extrapolate from existing supervision literature strategies for effectively fostering CIT growth and adapting our understanding of how these factors may also serve to support CITs and their supervisors as they navigate grief-related content and possible VG experiences in supervision.

Just as it has been studied in psychotherapy research, common factors of supervision can be examined to better conceptualize the supervisor's role and ability to shift a CIT's experience of VG. In considering common and specific factors of supervisory models, it has been suggested that the supervisory relationship is paramount to positive clinical outcomes (Crunk \& Barden, 2017). Doctoral student supervisors, in being asked to address the intense emotional reactions of VG with their CITs, may benefit from focusing on the quality of the supervisory relationship to encourage openness, honesty, and increased willingness to process feelings of grief that arise in relation to work with their clients.

Per Bernard and Goodyear's $(1992,2019)$ discrimination model, it can also be helpful to consider how the supervisory roles of counselor, consultant, and teacher may inform a doctoral student supervisor's approach to VG with trainees. Often as a new supervisor, it can be difficult to navigate these roles and best determine which to utilize within supervision (Bernard \& Goodyear, 2019; Nelson et al., 2006). The counselor role may be most familiar, given previous clinical experience, but the consultant and teacher role hold value in striking an "optimal balance between support and challenge" (Bernard \& Goodyear, 2019, p. 106) for the CIT. Purposefully integrating the roles of counselor, consultant, and teacher can support doctoral student supervisors in addressing CIT factors, such as resistance, anxiety, and 
transference, which inherently contribute to a trainee's experience of VG (Bernard \& Goodyear, 2019; Chan \& Tin, 2012; Gentry, 2002; Kirchberg et al., 1998).

To facilitate this integration of roles within the context of supervision, it is also crucial to recognize that doctoral student supervisors, early in their own training as clinical supervisors, may struggle with this task (Bernard \& Goodyear, 2019; Nelson et al., 2006). In response to COVID-19 impacts to clinical services, doctoral student supervisors may be asked to provide consultation to CITs regarding navigating a client crisis via teletherapy. Overlapping with the role of consultant is also the necessity for doctoral student supervisors to teach CITs about ethical usage of teletherapy platforms for the delivery of clinical services. Further, doctoral student supervisors may recognize the need to provide counseling support to CITs around anxiety that manifests from the plethora of changes in a short period of time. These examples highlight the complex tasks facing doctoral student supervisors in the context of the current COVID-19 pandemic and draw attention to the support doctoral student supervisors may benefit from in order to remain best equipped to meet their CITs' needs. Group or individual supervision with faculty members or senior clinic staff members may prove useful to provide an opportunity for doctoral student supervisors to examine their perspectives, emotional reactions, and the challenges of their new professional identity, coupled with the potential parallel process of experiencing their own VG through their work with CITs (Trippany et al., 2004).

As supervision provides opportunities for professional and personal growth critical to the learning experience of CITs, doctoral student supervisors must consider how best to support CITs in both of these domains. The bereavement literature suggests that a larger focus is often placed on the development of professional competencies, knowledge, and skills, as compared to an emphasis on the personal nature, or the role of self, in loss and grief (Balk et al., 2007; Stroebe et al., 2008). Thus, it is common for CITs and supervisors alike, particularly those who have not received formal academic instruction on topics of loss and grief, to be less open to topics of death and loss with clients, have less insight into their own beliefs regarding death, and have a greater fear of death (Doughty Horn et al., 2013).

This suggests that for supervisors to effectively address VG within supervision, they should engage in their own self-study of loss and grief to support their acquisition of knowledge and increased personal understanding of responses to death and loss. Because coursework that focuses specifically on loss and grief is not required by CACREP standards (Doughty Horn et al., 2013), it is unlikely that doctoral students coming from master's programs in counseling or marriage and family therapy have had substantive training specific to loss and grief (Ober et al., 2012). Seeking out learning opportunities will further prepare doctoral student supervisors to embody the roles of counselor, consultant, and teacher to both educate and process their CITs' reactions related to loss, grief, and death. Much like vicarious trauma has been approached within supervision, doctoral student supervisors who have engaged in the study and self-reflection of loss and grief can serve in the important role of helping CITs "stay in their own chairs" (Rothschild, 2006, p. 201). They can more effectively support identification of CITs' gaps in knowledge or reactions to the material presented by the client and utilize supervision as a space for both education and emotional processing.

Doctoral student supervisors working with CITs must recognize the inherent challenges CITs may have in sharing clinical and personal information within supervision (Lonn \& Haiyasoso, 2016). New counselors may be less aware of their emotional reactions in session (Dowden et al., 2014), further necessitating attention to VG by supervisors. Doctoral student supervisors, in guiding CITs to gain insight into their own reactions, may find benefit in incorporating discussion of countertransference and 
VG in an effort to differentiate the experiences for CITs. Countertransference-a counselor's emotional, cognitive, or behavioral reactions that occur in response to the client or clinical content and are rooted in the counselor's own life and relational experiences (Bernard \& Goodyear, 2019; Hayes et al., 2011) - can be understood as distinct from VG, which, adapted from the vicarious trauma literature, is the response to the loss-oriented client material unrelated to personal experiences (Trippany et al., 2004). Although countertransference may also occur for a CIT as it relates to loss and grief, the literature supports the likelihood that as clients experience existential crises of meaning around loss, professional helpers are likely to share in the existential challenges, including the experience of VG (Chan \& Tin, 2012). It is beneficial for doctoral student supervisors to support CITs in making this distinction, as each may require different attention within the supervision process.

The COVID-19 pandemic has elicited a surge of global loss, grief, and trauma, increasing the likelihood of supervisors and CITs encountering VG in supervision. Generally speaking, it is important and necessary for doctoral students to attend to the previously mentioned tasks of supporting CITs who may encounter VG, while recognizing the likelihood of a parallel process between supervision and the trainee's clinical work (Bernard \& Goodyear, 2019). Just as it can be hard for a CIT to manage responses to grief, so too may it be challenging for a new supervisor to cope without thorough discussion of loss and grief topics in supervision. Given the current widespread and collective grief specific to COVID-19, and the ubiquity of loss and grief in general, we recommend that counselor education programs help doctoral student supervisors to become more aware of the potential for VG to emerge in supervision. Strategies may include introducing case studies of VG in supervision to support doctoral students in applying strategies and exploring the impacts for themselves and their CITs.

\section{Implications for Training: Doctoral Student Curricular Preparation}

A review of the existing literature revealed that there is both minimal research and limited curricular focus on loss and grief education in the profession of counseling (Doughty Horn et al., 2013). Although this conversation has largely focused on master's-level curricula, it is important to consider the impact of this lack of focus within doctoral education as well. Counselor education doctoral students, lacking education on clinical competencies in loss and grief from within their master's programs, are preparing themselves to become educators of the next generation of counselors. Therefore, it is imperative that we rectify this lack of competency around loss and grief in order to best meet the moral and ethical obligation of counselors and counselor educators to promote and facilitate client growth both in their own clinical work and through the instruction and supervision of students' work (Cicchetti et al., 2016).

Doctoral programs, although held by CACREP (2015) standards to include training in counseling, supervision, teaching, research, and advocacy, currently have no requirement to address topics of loss and grief, including VG within these domains. In order to most effectively implement the strategies discussed above, doctoral student supervisors would benefit from more focused training, both to enhance their supervisory competencies and fill gaps within introductory counselor education. Despite the existence of master's CACREP standards that address life span development issues, there exist no CACREP standards to date that address topics of loss and grief, including VG. Hence, in this article, we examine how VG can perhaps be incorporated into doctoral supervisory curriculum.

Within counselor education doctoral programs, supervision is a core area of counselor educator education and training (CACREP, 2015). Given the ubiquity and salience of grief (Doughty Horn et al., 2013), VG is an arguably crucial phenomenon to be acknowledged and addressed by both CITs and doctoral supervisors. Hence, it is worthwhile to examine the content of courses that meet this standard. 
Whether a didactic course prior to direct supervisory experience or an experiential course, CACREP (2015) calls for course material to include a variety of components (e.g., purposes of clinical supervision, skills and modalities, ethical responsibilities, culturally relevant strategies). Despite the likelihood of issues of loss and grief to be present in clinical scenarios, CACREP supervision standards remain broad, meaning important topics, like loss and grief, may be neglected in course development and discussion. Just as students build on their prior knowledge of theory, interventions, cultural competence, and trauma-informed practice, so too can loss and grief be discussed as it relates to growing supervision knowledge, skills, and competencies.

The incorporation of these topics into doctoral courses may need to include foundational instruction related to loss and grief to facilitate basic competencies in addition to more complex applications of loss and grief clinical content to supervision frameworks, ethical issues, and modalities of supervision. Counselor educators and doctoral program coordinators may consider integrating VG both to draw attention to the possibility of one's own encounter with VG as a counselor and counselor educator, and to provide opportunities for processing and self-reflection. Through purposeful instruction and modeling of strategies for supervision, doctoral student supervisors are better equipped not only to manage their own reactions, but also to recognize and facilitate understanding of their CITs' reactions, ultimately supporting client well-being (Cicchetti et al., 2016). As such, we suggest that faculty of doctoral programs critically examine clinical topics discussed within courses meeting the CACREP supervision standards and purposefully integrate loss, grief, and VG into course content. Further, the use of case studies as a means of illustrating practical strategies that counselors and supervisors can use is a well-documented practice within the counseling scholarship (Kelly, 2016). Hence, in order to support doctoral students in their preparedness to apply the practical strategies discussed in this article, we present a case study as an example that can be used with doctoral students to support their training around VG in supervision.

\section{Case Study}

The following fictional case study illustrates features of VG (i.e., Type 1 and Type 2; Kastenbaum, 1987; Rando, 1997; Sullender, 2010) evident with Cynthia, a CIT, during clinical supervision with a doctoral supervisor. Doctoral supervisors working with CITs experiencing VG are advised to use the information previously outlined to pay attention to the grief reactions presented in the case. Drawing on Bernard and Goodyear's $(1992,2019)$ discrimination model, we discuss interventions that supervisors can use to attend to VG in supervision. Supervisor collaboration with practicum instructors to facilitate the management and potential amelioration of VG is also discussed. The case study highlights the important role supervision plays in facilitating the CIT's awareness about the process of both leaving and returning to one's "chair" (Rothschild, 2006, p. 201).

\section{The Case of Cynthia}

Cynthia is a master's-level CIT who is approaching the end of her practicum experience in the midst of COVID-19. During supervision, Cynthia discusses her clients' experiences with multiple forms of loss and associated grief resulting from the pandemic, ranging from the deaths of loved ones to COVID-19, to job loss, loss of financial security, loss of special plans, loss of social connection, and an overall loss of "normal life" as they knew it. When Cynthia's supervisor asks her how it has felt for her to help clients process their feelings of grief, Cynthia shares that when her clients share their grief with her, she becomes simultaneously reminded of her own losses (e.g., loss of social connection, daily routine, and normalcy) resulting from the pandemic, as well as her own associated grief response that she finds becomes activated in and outside of session. Cynthia shares that her own grief has been triggered by hearing her clients' experiences and that her satisfaction with and sense of personal accomplishment surrounding her clinical work is starting to diminish. 
Cynthia shares that she has also begun avoiding talking or thinking about their grief-related experiences in session. In supervision, she shares that since the pandemic, she worries that she is not doing enough for her clients and reports feeling a general sense of hopelessness associated with her work with them. Although she feels as though she is hearing her clients share stories about their loss and grief "constantly," she also indicates that she is trying to stay motivated to continue to work with her clients and believes in her ability to help them. She also reports, however, that bearing continuous witness to their grief, fear, and overall uncertainty associated with the losses they are enduring because of the pandemic is becoming emotionally difficult to manage.

A Brief Analysis: Type 1 and Type 2 VG. As illustrated above, the case of Cynthia depicts manifestations of Type 1 and Type 2 VG during supervision. First, Type 2 VG is evidenced by Cynthia's report of being reminded of her own losses following those of her clients and her resulting grief response. Within this instance of Type 2 VG, in response to the reported grief of her clients, Cynthia is reminded of her own losses as well as her own unfinished grieving. Second, Type 1 VG is evidenced by Cynthia's report that her own grief response has been triggered after hearing her clients' experiences of grief. Unlike Cynthia's experience of Type 2 VG, in which her own unfinished grief was elicited, in this instance, Cynthia exclusively feels what it is like to be in the griever's (i.e., client's) position. When using a case study such as this with doctoral students, it may be beneficial to have them identify and discuss the types of VG present and begin to process how they might attend to both within supervision.

Attending to VG in Supervision. According to Bernard and Goodyear $(1992,2019)$, the three primary roles that are associated with clinical supervision are: counselor, teacher, and consultant. Given that these roles all fall within the domain of supervision, CITs can be afforded a broad variety of developmentally appropriate interventions throughout supervision. In considering common and specific factors of supervisory models, it has been suggested that the supervisory relationship is paramount to positive clinical outcomes (Crunk \& Barden, 2017). Doctoral student supervisors, when addressing the intense emotional reactions of VG with their CITs, may benefit from focusing on the quality of the supervisory relationship to encourage openness, honesty, and increased willingness to process feelings of grief related to client work. When using a case study for experiential purposes, doctoral students can be asked to consider how, along with the use of common factors, the trifecta of roles presented by the discrimination model can be called on by supervisors to offer CITs guidance surrounding the challenging terrain of VG, regardless of the supervisor's theoretical supervisory orientation.

Counselor. Although the intent is not to provide therapy, doctoral students can consider how the role of counselor remains constant throughout the supervisory relationship and can facilitate CITs' understanding of and ability to manage their personal feelings and reactions as they emerge throughout their work with clients (Bernard \& Goodyear, 2019). Initially, after the origination of the COVID-19 pandemic and its loss-related effects on Cynthia's clients, Cynthia exhibited VG as well as hopelessness surrounding her clinical work during supervision. By facilitating Cynthia's processing through reflecting her feelings of hopelessness and asking her to reflect on how her feelings may be affecting her work with clients, the doctoral student supervisor might guide Cynthia in expressing her underlying emotions that are associated with her VG response and impacting her clinical work. Given the potential for CITs to feel challenged in sharing clinical and personal information within supervision (Lonn \& Haiyasoso, 2016), doctoral students examining this case study can consider how as a supervisor they might also use a check-in with Cynthia at the beginning of supervision (Doyle, 2017), in order to normalize her personal grief reactions and encourage her to be proactive about self-care surrounding her VG. Furthermore, in the case of COVID-19, this case study can highlight for doctoral students how a supervisor might attend to their own feelings of grief and demonstrate their willingness to model 
transparency and vulnerability to Cynthia in order to assist her in acknowledging and managing countertransference and VG. Ultimately, in more closely examining the role of counselor, doctoral students can more clearly imagine how they might be able to help Cynthia examine her feelings and emotions associated with her VG to her clients and her clinical work to reduce the potential for disturbance in her therapeutic relationship.

Teacher. In the role of teacher, the supervisor assumes the primary responsibility for the CIT's learning (Bernard \& Goodyear, 2019). In the case of Cynthia, as teacher, doctoral students can contemplate and discuss how as a supervisor they might work to help her understand her reactions to her clinical work as VG. In addition to providing education about how counselors are called to attend to their clients' needs during a crisis, the supervisor might also provide Cynthia with psychoeducation about VG, as well as examples of symptoms and information pertaining to distinguishing it from countertransference, compassion fatigue, or burnout. This knowledge would be provided to Cynthia to help normalize and validate manifestations of indirect grief which makes these reactions easier to manage, with the case study providing opportunity for doctoral students to evaluate their own knowledge of these areas and seek support from peers or faculty to grow their knowledge.

Furthermore, doctoral students examining this case study may also be prompted to examine how they could bolster Cynthia's learning and enhance her preparedness to work with her grieving clients by bringing Cynthia's experiences to the attention of her practicum instructor. This provides opportunity for doctoral students to consider how to collaborate with faculty so that instructors might provide additional educational support surrounding the concept of VG during group supervision. Through discussion around how to effectively integrate didactic components into the supervisory process and attend to Cynthia's learning, doctoral students are able to practice how a supervisor can work toward ameliorating a CIT's VG.

Consultant. In the role of consultant, the supervisor might work with Cynthia to identify strategies that minimize the impact of VG and allow her to engage in self-care practices. By examining this case study, doctoral students can consider how to balance the teaching role, in which they adopt the role of the expert, with the consultant role, in which the supervisor works to foster Cynthia's independence, autonomy, and empowerment (Bernard \& Goodyear, 2019). Given that Cynthia demonstrated motivation to engage in supervision and learn more about her VG, as consultant, the supervisor might provide her with structured guidance surrounding how to approach her work with clients. Doctoral students may benefit from discussion around how to promote amelioration of Cynthia's VG through providing her with resources regarding self-regulation and offering to help her brainstorm ways to be more present with her clients in session during discussions of grief. By examining a case study, doctoral students are provided the opportunity to further consider how, as consultant, they might communicate to Cynthia that she handled this situation ethically and professionally by sharing her feelings of VG with the supervisor.

\section{Limitations}

Given the dearth of research on grief literacy in counselor education and without sufficient standards around loss and grief training for counselors (Doughty Horn et al., 2013; Ober et al., 2012), our conceptualizations, discussion, and recommendations for doctoral student supervisors and CITs encountering VG in supervision are inherently limited. Thus, we cannot be certain these recommendations would significantly influence the supervisory experience and its effect on client and counselor well-being. We believe there is sufficient evidence within the current literature 
suggesting that attention to VG within supervision is warranted, but further research is necessary to more completely understand the role of supervision in identifying and managing VG responses.

Further, our exploration of VG is limited to an academic setting as we believe specific attention to these competencies lies in the inclusion of loss and grief training within counselor education (Doughty Horn et al., 2013). However, given the ubiquity of grief in life and within counseling (Chan \& Tin, 2012; Doughty Horn et al., 2013; Hill et al., 2018), it would be remiss for us to not acknowledge that this discussion about doctoral student supervisors is just one of many situations in which a counselor or clinical supervisor may find themselves faced with experiences of VG. Our conceptualization of VG and many of our suggestions may even ring true for clinical supervisors at various stages of their career within that role. Further research must consider how supervision occurs in contexts outside of academia and the impact of VG for counselors and supervisors at more advanced stages of their career.

\section{Future Directions}

Given the continued pervasiveness of the COVID-19 pandemic, it is impossible to understand its long-term effects, but the immediate impacts to the profession of counseling speak to the necessity of recognizing reactions to grief within clinical work and supervision. Although the supervision literature abounds with approaches for supervising counselors, as highlighted by this article, the counseling literature lacks empirical studies on VG in supervision, despite its occurrence and impact on clinicians and supervisors alike. In the absence of such research, we call for VG in supervision to be an emerging area of focus for the profession of counseling, particularly within doctoral counselor education.

However, although the scope of this article is aimed at recognizing and managing VG by doctoral student supervisors, it is our hope that drawing attention to the complexities of this experience brings further conversation to experiences of VG in all types of clinical supervision. It is of benefit to all supervisors, doctoral students, and clinicians both new to the role and with seasoned experience that increased attention is directed toward validating specific supervisory techniques developed to attend to counselors' experience of VG in supervision. It is our goal that this discussion acknowledges the impact of VG on clinicians and promotes further research and development of best practices for managing VG in supervision, both within counselor education and beyond.

\section{Conclusion}

CITs and counselor educators face the possibility of experiencing VG in their respective work with clients and CITs who have experienced loss. Counselor educators in supervisory roles can help CITs mitigate VG through facilitating awareness of the impacts of grief-related clinical content into the supervision process and attending to CITs' unique needs in the roles of teacher, counselor, and consultant. In light of the COVID-19 pandemic and its resulting landscape of increased loss and related mental health needs, it is especially critical for counselor educators and supervisors to be equipped to attend to the needs of CITs who are experiencing VG. In this article, we aimed to address this need by defining VG, discussing its potential impact on CITs and doctoral supervisors, and presenting a case study illustrating interventions that counselor educators can use when addressing VG in supervision.

\section{Conflict of Interest and Funding Disclosure}

The authors reported no conflict of interest or funding contributions for the development of this manuscript. 
The Professional Counselor I Volume 11, Issue 2

\section{References}

American Counseling Association. (n.d.). Fact sheet \#9: Vicarious trauma. https://www.counseling.org/docs/traumadisaster/fact-sheet-9---vicarious-trauma.pdf?sfvrsn=f0f03a27 2

American Psychiatric Association. (2013). Diagnostic and statistical manual of mental disorders (5th ed.).

Balk, D., Wogrin, C., Thornton, G., \& Meagher, D. (Eds.). (2007). Handbook of thanatology: The essential body of knowledge for the study of death, dying, and bereavement (1st ed.). Routledge/Taylor \& Francis Group.

Bernard, J. M., \& Goodyear, R. K. (1992). Fundamentals of clinical supervision (1st ed.). Allyn \& Bacon.

Bernard, J. M., \& Goodyear, R. K. (2019). Fundamentals of clinical supervision (6th ed.). Pearson.

Chan, W. C. H., \& Tin, A. F. (2012). Beyond knowledge and skills: Self-competence in working with death, dying, and bereavement. Death Studies, 36(10), 899-913. https://doi.org/10.1080/07481187.2011.604465

Cicchetti, R. J., McArthur, L., Szirony, G. M., \& Blum, C. R. (2016). Perceived competency in grief counseling: Implications for counselor education. Journal of Social, Behavioral, and Health Sciences, 10(1), 3-17. https://doi.org/10.5590/JSBHS.2016.10.1.02

Council for Accreditation of Counseling and Related Educational Programs. (2015). 2016 CACREP standards. http://www.cacrep.org/wp-content/uploads/2017/08/2016-Standards-with-citations.pdf

Crunk, A. E., \& Barden, S. M. (2017). The Common Factors Discrimination Model: An integrated approach to counselor supervision. The Professional Counselor, 7(1), 62-75. https://doi.org/10.15241/aec.7.1.62

Crunk, A. E., Burke, L. A., \& Robinson, E. H. M., III. (2017). Complicated grief: An evolving theoretical landscape. Journal of Counseling E Development, 95(2), 226-233. https://doi.org/10.1002/jcad.12134

Doughty Horn, E. A., Crews, J. A., \& Harrawood, L. K. (2013). Grief and loss education: Recommendations for curricular inclusion. Counselor Education and Supervision, 52(1), 70-80. https://doi.org/10.1002/j.1556-6978.2013.00029.x

Dowden, A. R., Warren, J. M., Kambui, H. A. (2014). Three tiered model toward improved self-awareness and self-care. In G. R. Walz \& J. C. Bleuer (Eds.), Ideas and research you can use: VISTAS 2014. http://www. counseling.org/docs/default-source/vistas/article_30.pdf

Doyle, K. A. (2017). Modeled wellness: Using perceived supervisor wellness and the supervisory relationship to predict supervisee personal wellness [Doctoral dissertation, Virginia Tech].

Gentry, J. E. (2002). Compassion fatigue: A crucible of transformation. Journal of Trauma Practice, 1(3-4), 37-61. https://doi.org/10.1300/J189v01n03_03

Hayes, J. A., Gelso, C. J., \& Hummel, A. M. (2011). Managing countertransference. Psychotherapy, 48(1), 88-97. https://doi.org/10.1037/a0022182

Hill, J. E., Cicchetti, R. J., Jackson, S. A., \& Szirony, G. M. (2018). Perceptions of grief education in accredited counseling programs: Recommendations for counselor education. Journal of Social, Behavioral, and Health Sciences, 12(1), 74-83. https://doi.org/10.5590/JSBHS.2018.12.1.05

Kastenbaum, R. (1987). Vicarious grief: An intergenerational phenomenon? Death Studies, 11(6), 447-453. https://doi.org/10.1080/07481188708252209

Kelly, V. A. (2016). Addiction in the family: What every counselor needs to know. American Counseling Association.

Kirchberg, T. M., \& Neimeyer, R. A. (1991). Reactions of beginning counselors to situations involving death and dying. Death Studies, 15(6), 603-610. https://doi.org/10.1080/07481189108252548

Kirchberg, T. M., Neimeyer, R. A., \& James, R. K. (1998). Beginning counselors' death concerns and empathic responses to client situations involving death and grief. Death Studies, 22(2), 99-120. https://doi.org/10.1080/074811898201623

Ladany, N., Constantine, M. G., Miller, K., Erickson, C. D., \& Muse-Burke, J. L. (2000). Supervisor countertransference: A qualitative investigation into its identification and description. Journal of Counseling Psychology, 47(1), 102-115. https://doi.org/10.1037/0022-0167.47.1.102

Lonn, M. R., \& Haiyasoso, M. (2016). Helping counselors "stay in their chair": Addressing vicarious trauma in supervision. In G. R. Walz \& J. C. Bleuer (Eds.), Ideas and research you can use: VISTAS 2016. https://www. counseling.org/docs/default-source/vistas/article 90 2016.pdf?sfvrsn=cbe2482c 4

Milstein, C. (Ed.). (2017). Rebellious mourning: The collective work of grief. AK Press.

Nelson, K. W., Oliver, M., \& Capps, F. (2006). Becoming a supervisor: Doctoral student perceptions of the training experience. Counselor Education and Supervision, 46(1), 17-31.

https://doi.org/10.1002/j.1556-6978.2006.tb00009.x 
Ober, A. M., Granello, D. H., \& Wheaton, J. E. (2012). Grief counseling: An investigation of counselors' training, experience, and competencies. Journal of Counseling E Development, 90(2), 150-159. https://doi.org/10.1111/j.1556-6676.2012.00020.x

Prigerson, H. G., Maciejewski, P. K., Reynolds, C. F., III, Bierhals, A. J., Newsom, J. T., Fasiczka, A., Frank, E., Doman, J., \& Miller, M. (1995). Inventory of Complicated Grief: A scale to measure maladaptive symptoms of loss. Psychiatry Research, 59(1-2), 65-79. https://doi.org/10.1016/0165-1781(95)02757-2

Rando, T. A. (1997). Vicarious bereavement. In S. Strack (Ed.), Death and the quest for meaning: Essays in honor of Herman Feifel (pp. 257-274). Jason Aronson.

Rothschild, B. (2006). Help for the helpers: Self-care strategies for managing burnout and stress. W. W. Norton.

Shear, M. K. (2012). Getting straight about grief. Depression and Anxiety, 29(6), 461-464. https://doi.org/10.1002/da.21963

Stroebe, M. S., Hansson, R. O., Schut, H., \& Stroebe, W. (Eds.). (2008). Handbook of bereavement research and practice: Advances in theory and intervention. American Psychological Association.

Sullender, R. S. (2010). Vicarious grieving and the media. Pastoral Psychology, 59, 191-200. https://doi.org/10.1007/s11089-009-0227-5

Terry, M. L., Bivens, A. J., \& Neimeyer, R. A. (1996). Comfort and empathy of experienced counselors in client situations involving death and loss. Omega - Journal of Death and Dying, 32(4), 269-285. https://doi.org/10.2190/WJ89-KCTY-DBWG-8QTX

Trippany, R. L., White Kress, V. E., \& Wilcoxon, S. A. (2004). Preventing vicarious trauma: What counselors should know when working with trauma survivors. Journal of Counseling \& Development, 82(1), 31-37. https://doi.org/10.1002/j.1556-6678.2004.tb00283.x

Weir, K. (2020). Grief and COVID-19: Mourning our bygone lives. American Psychological Association News. https://www.apa.org/news/apa/2020/04/grief-covid-19 